\title{
COMMENT
}

\section{Where to make a difference: research and the social determinants in pediatrics and child health in the COVID-19 era}

Peter Lachman (iD) ${ }^{1}$

The COVID-19 pandemic has emphasized the way different communities have been affected dependent on ethnic or social background. In this paper, the social determinants of COVID-19 will be considered with a review of the current literature and the opportunities for future research. There has been very little written about this approach to the infection and its consequences. Although children are not as affected as adults, the measures to control the pandemic may have significant consequences for children's mental and physical well-being, as well as long-term challenges for their education. Research in pediatrics and child health should address this challenge going forward.

Pediatric Research (2021) 89:259-262; https://doi.org/10.1038/s41390-020-01253-0

IMPACT:

- Raises the importance of Social Determinants of Health in pediatrics.

- Considers the impact of Social Determinants of Health on COVID-19.

- Offers opportunities for research in the future.

In 2005, Michael Marmot introduced the concept of the Social Determinants of Health $(\mathrm{SDH})^{1}$ in which he proposed what was in plain sight, i.e., that health outcomes are determined by "the conditions in which people are born, grow, live, work and age". 2 For children, these social determinants influence life opportunities, disease profiles, health outcomes, and life expectancy. Since the initial paper, there has been little progress in addressing the social determinants of health. In a review in 2010, Marmot concluded that social and economic status determines the health outcomes, and the lower the socioeconomic status the worse the outcome. ${ }^{3}$ In the USA, there have been similar reviews in which the social determinants have been documented to have a severe adverse impact on children. ${ }^{4}$

In February 2020, just prior to the pandemic, Marmot published a progress report on health inequalities and inequity in the United Kingdom. He demonstrated that inequity in the United Kingdom has been exacerbated rather than decreased, despite intervention. More children are living in poverty and more are experiencing food insecurity, with a negative consequence on growth and development. ${ }^{5}$ These findings must raise questions for other societies. If the United Kingdom, a relatively wealthy country with an established welfare system has deteriorating conditions for children, the situation in other countries may be similar or worse. In 2016, Pediatric Research published a review focused on the Social Determinants of Health, where it was stated that social determinants were the "elephant in the room" in pediatric research and there was a call for future research in this domain. ${ }^{6}$
Now 4 years later, in the midst of a pandemic, the importance of considering the SDH in pediatric research has been highlighted once more by SARS-CoV-2. In societies affected by the virus, those who suffer inequity and who are negatively influenced by the SDH have been most severely affected. In this paper, I will cover the key areas that require attention as we move to the post COVID era. It will not be possible to include all the papers that have been published. Nevertheless, the potential for a new dimension in pediatric research will be highlighted and references to reports will be provided.

The interaction of structural racism within the health system and the risk factors that are social determinants of the outcome of those impacted by COVID have been emphasized. ${ }^{7}$ The COVID pandemic has exposed underlying inequalities in society. For example, in the United States, the CDC has estimated that people of Hispanic, Native American or Black American origin have an approximately four to five times higher rate of infection. ${ }^{8,9}$ This is similar to the reported rates in the United Kingdom, where the differential rate is of a similar magnitude. ${ }^{10}$ Currently it is not certain why this is so, but the SDH plays a major role as the known risk factors and comorbidities for poorer outcomes in COVID-19 infection, such as diabetes and obesity, and other chronic diseases that are more prevalent in poorer communities and ethnic minorities. ${ }^{11}$ Social determinants may result in higher rates of infection, due to overcrowding and the inability to apply preventive measures, as well as the social consequences due to loss of family income, loss of schooling, and loss of non-COVID public health interventions, thereby perpetuating the cycle. It is

${ }^{1}$ International Society for Quality in Health Care, 4th Floor, Huguenot House, 35-38 St Stephens Green, Dublin D02 NY63, Ireland

Correspondence: Peter Lachman (plachman@isqua.org)

Received: 29 July 2020 Revised: 3 October 2020 Accepted: 13 October 2020

Published online: 10 November 2020 
clear that social background, socioeconomic status, and poverty, along with ethnicity converge to produce worse outcomes. ${ }^{12,13}$ Knowledge of the infection and preventive measures differ as to ethnicity and socioeconomic class. ${ }^{14}$

Therefore, the COVID-19 pandemic presents both a challenge and an opportunity for the pediatric research community. While it is tempting to report the impact of the pandemic in terms of the infection and its clinical sequelae alone, we can rather examine the impact of the pandemic on children through the lens of inequity and the social determinants. The evidence in children has yet to be reported in research studies, given that children have a lower incidence of severe infections. As noted by Greenhalgh, ${ }^{15}$ evidence during the pandemic is being determined in a different way to that of traditional research. Greenhalgh contends that in a complex adaptive system such as the COVID-19 pandemic, we need to move to a "more fit-for-purpose scientific paradigm", where linear associations may not be possible, due to the complexity of the real world. As the pandemic is one large natural experiment, reports of the impact of COVID-19 on children are emerging in informal ways through correspondence to journals.

Although the evidence base is limited, these early communications point to the type of research that is required in the coming months. There is also the opportunity to reconsider how we undertake research into the consequences of the pandemic on child health and disease. If the impact of the pandemic is to be understood, we will need to examine a wide range of issues on how the pandemic has affected children, both now and over the years to come. Research must address the disproportionate impact the pandemic has had on the social fabric of society in every country it has affected. In this commentary, I will point to the key areas of research that are required, in addition to the inevitable research for effective treatment modalities and for a vaccine. The lessons from the study of the pandemic in the wider sense, can in turn be applied to become a holistic research strategy.

Early in the pandemic, it was noted that data that would help to evaluate the relationship between social determinants of health and COVID-19 were not being routinely recorded. ${ }^{16}$ This could indicate a subconscious bias against the recording of essential data needed to identify the most vulnerable groups in society that maybe affected by COVID-19, in favor of data focused on interventions for the majority. The following areas of potential research are proposed:

\section{SEVERE ILLNESS AND SEQUELAE}

The COVID pandemic has had a mild impact on children. However, the reports of pediatric inflammatory multisystem syndrome temporally associated with SARS-CoV-2 (PIMS-TS) have indicated that there is a severe, though rare, consequence of infection. In each of the papers on this condition, it has been noted that up to three-quarters of those infected come from ethnic minorities. ${ }^{17-20}$ In each case, the reason for this has not been determined and while it could be a genetic predisposition, the social determinants of this condition will require further research and should not be ignored.

\section{COLLATERAL DAMAGE OF THE LOCKDOWN AND SOCIAL DISTANCING}

The pandemic has had a significant impact on children beyond the actual infection. We need to view the impact the pandemic has had-not only from a pathophysiological lens but also from the lens of the societal impact. ${ }^{21}$ An early review indicated that the risk of dying from other conditions was greater than that from COVID-19. ${ }^{22}$ A number of papers have looked at the potential collateral damage from the public health policies of lockdown and physical/social distancing, including both the physical and mental well-being of children. Many of the lockdown interventions have been applied and experienced according to one's social class. Professionals can work from home and look after their children, while those in more menial employment do not have that choice. Unemployment and loss of "gig economy" work have affected the most disadvantaged. This in turn would have a disproportionate impact on children.

The consequence of the pandemic on SDH for children is emerging. Although children with the severe illness have not been widely reported, it is possible that it may have been disproportionate in poorer communities and in minority groups. It has been reported that children from ethnic minority groups or who are socially disadvantaged have higher rates of infection. Socioeconomically disadvantaged children had a higher likelihood of SARS-CoV-2 infection. ${ }^{23}$ Examples of the consequences of the focus on COVID are given in papers from the United Kingdom, which report on possible collateral damage, including decreased vaccination, decreased attendance at hospitals and delayed diagnosis of diseases, as well as the negative impact of isolation on mental well-being. ${ }^{24,25}$ Therefore, there is the potential for the following areas of research. A reference to reports in the literature is provided as a guide to the potential for research. In all research, it will be important to examine the impact based on socioeconomic status, as it is postulated that SDH will play a large part in how children are affected. The decreased attendance at school will affect those from lower socioeconomic status more than those who can afford substitute education. Immunization rates will have decreased, as will other public health interventions.

\section{IMPACT OF DISPARITIES IN TECHNOLOGIES OF DIGITAL HEALTH AND LEARNING}

The solutions that have been developed for addressing the impact of COVID-19 have included telehealth and digital learning. Access to the internet and broadband are now considered to be a social determinant of health ${ }^{26,27}$ The decreased attendance at school has affected those from lower socioeconomic status more than those who can afford substitute education and who can access learning via the internet. Immunization rates will have decreased as will have other public health interventions. Studies have indicated that access to computers is variable, as is access to the internet. Access to patient portals, telemedicine, and digital health is dependent on social class and poverty levels, both urban and rural., with marked disparities in cities. ${ }^{28-31}$

\section{POTENTIAL FOR RESEARCH ON THE SOCIAL DETERMINANTS OF COVID-19}

- To assess the long-term impact of isolation on mental wellbeing, as it is postulated that there will be an increase in mental ill-health issues in children. ${ }^{32}$ Early reviews have described the impact of social isolation with increased levels of depression and anxiety. ${ }^{33-35}$ Further longitudinal studies of the mental health cost of the pandemic are required.

- To assess the impact on child protection as a result of increased domestic violence. It has been reported that there was a decrease in assessments in child protection and that there will be a delayed resurgence. ${ }^{36-38}$

- To assess whether the impact on the treatment of children with chronic conditions and comorbidities had a worse outcome-or were they affected similarly to adults with comorbidities. To date, there have been few reports on the impact on children with comorbidities. A report from the U.K. indicated that children with comorbidities may have a higher risk of being affected. They reported infections in children 
with a range of comorbidities, such as cerebral palsy, prematurity, Wilson Disease and dilated cardiomyopathy. ${ }^{39}$

- A number of reports have documented the marked decrease in attendance of children in the Emergency Room and in outpatients. Whether this has had a negative effect in terms of delayed diagnosis and/or morbidity and mortality is to be determined. ${ }^{40-42}$

- To consider the impact of COVID-19 on pregnancy and whether it led to increases in prematurity. One report indicated an increase in the number of stillbirths - whether caused by COVID-19 or not is unclear. ${ }^{43,44}$

- While most reports have been from upper-income countries, there are concerns that the pandemic will have a devastating impact on children in resource-poor countries. The consequences are similar to the upper-income countries, but lack of resources and other comorbidities may lead to different outcomes. ${ }^{45-47}$ In particular, the impact of the decrease in preventive measures such as vaccination, maybe worse than the impact of the infection from the SARS-CoV-2 infection. ${ }^{48}$ Research into the global impact on children is urgently required as the social determinants of healthcare is a global issue. ${ }^{49,50}$

- Vulnerable youth are a broad group of adolescents who are often forgotten. This group includes lesbian, gay, bisexual, transgender, queer, and/or questioning [LGBTQ] young people; those who are homeless, maltreated or in foster care; or those struggling with substance use disorders. They may be at particular risk during the pandemic, with increased exposure to infection and limited support. ${ }^{51}$

- As noted, access to the internet, broadband, and differential access to telehealth will require further research to assess positive or negative sequelae of the new ways of delivering care. In particular, as noted in the last edition on SDH, the impact of telehealth on poorer communities needs to be evaluated. ${ }^{52}$

In conclusion, the challenge is great, but it is one that we need to grasp. A recent study has shown that African American children have three fold worse outcomes in routine surgery when compared to their White peers. ${ }^{53,54}$ We can assume that this could possibly apply to COVID-19, so further research is required. A word of caution. We need to avoid the temptation to be judgemental as we explore the disparities exposed by the SARSCoV-2 infection..$^{55}$ The impact of the COVID-19 pandemic goes far beyond managing the disease. It has changed the way that we live, educate our children and interact in society. We need to examine how healthcare is organized so that the underlying structural constraints are addressed. ${ }^{56}$ And, while we manage the pandemic, we need to ensure that children are not disadvantaged and that they have access to healthcare. ${ }^{57}$ The causes are deepseated and complex, but the body of evidence is growing. We now need research and to test interventions that will improve the Social Determinants of Health-and ultimately health itself.

\section{ACKNOWLEDGEMENTS}

Genevieve Paisley of the Paediatric International Patient Safety and Quality Community (PIPSQC) contributed to the literature search. I thank her for the search and for compiling the comprehensive list of references and website information on COVID-19 in children which can be obtained from the PIPSQC website http://www. pipsqc.org/RESOURCES/COVID-19-AND-CHILDREN. This includes papers and media reports that could not be included in the reference list.

\section{ADDITIONAL INFORMATION}

The online version of this article (https://doi.org/10.1038/s41390-020-01253-0) contains supplementary material, which is available to authorized users.

Competing interests: The author declares no competing interest.
Publisher's note Springer Nature remains neutral with regard to jurisdictional claims in published maps and institutional affiliations.

\section{REFERENCES}

1. Marmot, M. Social determinants of health inequalities. Lancet 365, 1099-1104 (2005).

2. World Health Organisation. https://www.who.int/social_determinants/ sdh_definition/en. Accessed 25 Sept 2020.

3. Marmot, M. Fair Society, Healthy Lives: The Marmot Review: Strategic Review of Health Inequalities in England post-2010 (2010).

4. Gee G. C. Leveraging the social determinants to build a culture of health: racism as a social determinant of health inequities. https://healthequity. globalpolicysolutions.org/wp-content/uploads/2016/12/RacismasSDOH.pdf. Accessed 25 Sept 2020 (2016)

5. Marmot, M., Allen, J., Boyce, T., Goldblatt, P. \& Morrison J. Health equity in England: the Marmot Review 10 years on. www.instituteofhealthequity.org/ resources-reports/marmot-review-10-years-on/the-marmot-review-10-years-onfull-report.pdf. Accessed 25 Sept 2020.

6. Tarazi, C., Skeer, M., Fiscella, K., Dean, S. \& Dammann, O. Everything is connected: social determinants of pediatric health and disease. Pediatr. Res. 79, 125-126 (2016).

7. Egede, L. E. \& Walker, R. J. Structural racism, social risk factors, and covid-19-a dangerous convergence for Black Americans. N. Engl. J. Med. 383, e77 (2020).

8. Centers for Disease Control and Prevention. Weekly updates by select demographic and geographic characteristics. https://www.cdc.gov/nchs/nvss/vsrr/ covid weekly/index.htm. Accessed 25 Sept 2020.

9. APM Research Lab. The color of coronavirus: COVID-19 deaths by race and ethnicity in the U.S. https://www.apmresearchlab.org/covid/deaths-by-race. Accessed 10 July 2020

10. Public Health England. COVID-19: understanding the impact on BAME communities. https://www.gov.uk/government/publications/covid-19-understandingthe-impact-on-bame-communities. Accessed 10 July 2020 (2020).

11. Bambra, C., Riordan, R., Ford, J. \& Matthews, F. The COVID-19 pandemic and health inequalities. J. Epidemiol. Community Health. https://doi.org/10.1136/jech2020-214401 (2020).

12. Johnson-Mann, C., Hassan, M. \& Johnson, S. COVID-19 pandemic highlights racial health inequities. Lancet Diabet. Endocrinol. 8, 663-664 (2020).

13. Shah, G. H., Shankar, P., Schwin, J. S. \& Sittaramane, V. The detrimental impact of the COVID-19 crisis on health equity and social determinants of health. J. Public Health Manag. Pract. 26, 317-319 (2020).

14. Alobuia, W. M. et al. Racial disparities in knowledge, attitudes and practices related to COVID-19 in the USA. J. Public Health 42, 470-478 (2020).

15. Greenhalgh, T. Will COVID-19 be evidence-based medicine's nemesis? PLoS Med. 17, e1003266 (2020).

16. Khalatbari-Soltani, S., Cumming, R. C., Delpierre, C. \& Kelly-Irving, M. Importance of collecting data on socioeconomic determinants from the early stage of the COVID-19 outbreak onwards. J. Epidemiol. Community Health 74, 620-623 (2020).

17. Levin, M. Childhood multisystem inflammatory syndrome-a new challenge in the pandemic. N. Engl. J. Med. 383, 393-395 (2020).

18. Dufort, E. M. et al. Multisystem inflammatory syndrome in children in New York State. N. Engl. J. Med. 383, 347-358 (2020).

19. Feldstein, L. R. et al. Multisystem inflammatory syndrome in U.S. children and adolescents. N. Engl. J. Med. 383, 334-346 (2020).

20. Davies, $P$. et al. Intensive care admissions of children with paediatric inflammatory multisystem syndrome temporally associated with SARS-CoV-2 (PIMS-TS) in the UK: a multicentre observational study. Lancet Child Adolesc. Health 4, 669-677 (2020).

21. The Childhood Trust. Children in lockdown: the consequences of the coronavirus crisis for children living in poverty. London. https://view.publitas.com/thechildhood-trust/children-in-lockdown-the-childhood-trust-report-june-2020/ page/1. Accessed 12 July 2020 (2020).

22. Bhopal, S., Bagaria, J. \& Bhopal, R. Children's mortality from COVID-19 compared with all-deaths and other relevant causes of death: epidemiological information for decision-making by parents, teachers, clinicians and policymakers. Public Health 185, 19-20 (2020).

23. Goyal, M. K. et al. Racial/ethnic and socioeconomic disparities of SARS-CoV-2 infection among children. Pediatrics. https://doi.org/10.1542/peds.2020-009951 (2020).

24. Crawley, E. et al. Wider collateral damage to children in the UK because of the social distancing measures designed to reduce the impact of COVID-19 in adults. BMJ Paediatr. Open. 4, e000701 (2020).

25. Chanchlani, N., Buchanan, F. \& Gill, P. J. Addressing the indirect effects of COVID19 on the health of children and young people. CMAJ 192, E921-E927 (2020). 
Where to make a difference: research and the social determinants in...

P Lachman
26. Benda, N. C., Veinot, T. C., Sieck, C. J. \& Ancker, J. S. Broadband internet access is a social determinant of health! Am. J. Public Health 110, 1123-1125 (2020)

27. Reddick, C. G., Enriquez, R., Harris, R. J. \& Sharma, B. Determinants of broadband access and affordability: an analysis of a community survey on the digital divide. Cities 106, 102904 (2020).

28. McCloud, R. F., Okechukwu, C. A., Sorensen, G. \& Viswanath, K. Beyond access: barriers to internet health information seeking among the urban poor. J. Am. Med. Inf. Assoc. 23, 1053-1059 (2016).

29. Hirko, K. A. et al. Telehealth in response to the covid-19 pandemic: implications for rural health disparities. J. Am. Med. Inform. Assoc. https://doi.org/10.1093/ jamia/ocaa156 (2020).

30. Perzynski, A. T. et al. Patient portals and broadband internet inequality. J. Am. Med. Inf. Assoc. 24, 927-932 (2017).

31. Chunara, R. et al. Telemedicine and healthcare disparities: a cohort study in a large healthcare system in New York City during COVID-19. J. Am. Med. Inform. Assoc. https://doi.org/10.1093/jamia/ocaa217 (2020).

32. Loades, M. E. et al. Rapid systematic review: the impact of social isolation and loneliness on the mental health of children and adolescents in the context of COVID-19. J. Am. Acad. Child Adolesc. Psychiatry https://doi.org/10.1016/j. jaac.2020.05.009 (2020).

33. Singh, S. et al. Impact of COVID-19 and lockdown on mental health of children and adolescents: a narrative review with recommendations [published online ahead of print, 2020 Aug 24]. Psychiatry Res. 293, 113429 (2020).

34. Pfefferbaum, B. \& North, C. S. Mental health and the covid-19 pandemic. N. Engl. J. Med. 383, 510-512 (2020).

35. Courtney, D., Watson, P., Battaglia, M., Mulsant, B. H. \& Szatmari, P. COVID-19 impacts on child and youth anxiety and depression: challenges and opportunities. Can. J. Psychiatry 65, 688-691 (2020).

36. Chandan, J. S. et al. COVID-19: a public health approach to manage domestic violence is needed. Lancet Public Health 5, e309 (2020).

37. Green, P. Risks to children and young people during covid-19 pandemic. BMJ 369, m1669 (2020).

38. Bhopal, S., Buckland, A., McCrone, R., Villis, A. I. \& Owens, S. Who has been missed? Dramatic decrease in numbers of children seen for child protection assessments during the pandemic. Arch. Dis. Child. https://doi.org/10.1136/ archdischild-2020-319783 (2020).

39. Harman, K. et al. Ethnicity and COVID-19 in children with comorbidities. Lancet Child Adolesc. Health 4, e24-e25 (2020).

40. Lynn, R. M., Avis, J. L., Lenton, S., Amin-Chowdhury, Z. \& Ladhani, S. N. Delayed access to care and late presentations in children during the COVID-19 pandemic: a snapshot survey of 4075 paediatricians in the UK and Ireland. Arch. Dis. Child. https://doi.org/10.1136/archdischild-2020-319848 (2020).

41. Ferrero, F., Ossorio, M. F., Torres, F. A. \& Debaisi G. Impact of the COVID-19 pandemic in the paediatric emergency department attendances in Argentina. Arch. Dis. Child. https://doi.org/10.1136/archdischild-2020-319833 (2020).
42. Dann, L., Fitzsimons, J., Gorman, K. M., Hourihane, J. \& Okafor, I. Disappearing act: COVID-19 and paediatric emergency department attendances. Arch. Dis. Child. 105, 810-811 (2020).

43. Khalil, A. et al. Change in the incidence of stillbirth and preterm delivery during the COVID-19. JAMA 324, 705-706 (2020).

44. Khalil, A. et al. SARS-CoV-2 infection in pregnancy: a systematic review and metaanalysis of clinical features and pregnancy outcomes. EClinical Med. 25, 100446 (2020).

45. Ahmed, S. et al. Protecting children in low-income and middle-income countries from COVID-19. BMJ Glob. Health 5, e002844 (2020).

46. Kirmani, S. \& Saleem, A. Impact of COVID-19 pandemic on paediatric services at a referral centre in Pakistan: lessons from a low-income and middle-income country setting. Arch. Dis. Child. https://doi.org/10.1542/peds.2020-009951 (2020).

47. Duke, T., English, M., Carai, S. \& Qazi, S. Paediatric care in the time of COVID-19 in countries with under-resourced healthcare systems. Arch. Dis. Child 105, 616-617 (2020).

48. Abbas, K. et al. Routine childhood immunisation during the COVID-19 pandemic in Africa: a benefit-risk analysis of health benefits versus excess risk of SARS-CoV2 infection. Lancet Glob. Health. https://doi.org/10.1016/S2214-109X(20)30308-9 (2020).

49. Zar, H. J., Dawa, J., Fischer, G. B. \& Castro-Rodriguez, J. A. Challenges of COVID-19 in children in low- and middle-income countries. Paediatr. Respir. Rev. 35, 70-74 (2020).

50. Weil, A. R. Tackling social determinants of health around the globe. Health Aff. 39, 1118-1121 (2020)

51. Silliman Cohen, R. I. \& Bosk, E. A. Vulnerable youth and the COVID-19 pandemic. Pediatrics 146, e20201306 (2020).

52. Marcin, J. P., Shaikh, U. \& Steinhorn, R. H. Addressing health disparities in rural communities using telehealth. Pediatr. Res. 79, 169-176 (2016).

53. Nafiu, O. O., Mpody, C., Kim, S. S., Uffman, J. C. \& Tobias, J. D. Race, postoperative complications, and death in apparently healthy children. Pediatrics 146, e20194113 (2020).

54. Johnson, T. J. Intersection of bias, structural racism, and social determinants with health care inequities. Pediatrics 146, e2020003657 (2020).

55. Chowkwanyun, M. \& Reed, A. L. Jr. Racial health disparities and covid-19-caution and context. N. Engl. J. Med. 383, 201-203 (2020).

56. Blumenthal, D., Fowler, E. J., Abrams, M. \& Collins, S. R. Covid-19-implications for the Health Care System [published online ahead of print, $2020 \mathrm{Jul}$ 22] [published correction appears in N Engl J Med. 2020 Jul 23]. N. Engl. J. Med. https://doi.org/ 10.1056/NEJMsb2021088 (2020).

57. Mclntosh, J. et al. European Children's Hospitals Organisation. Safeguarding children's right to health in hospital during COVID-19. Lancet Child Adolesc. Health. https://doi.org/10.1016/S2352-4642(20)30300-X (2020). 